\title{
A ZONA DE CISALHAMENTO TAUÁ, CEARÁ: SENTIDO E ESTIMATIVA DO DESLOCAMENTO, EVOLUÇÃO ESTRUTURAL E GRANITOGÊNESE ASSOCIADA
}

\author{
SÉRGIO P. NEVES*
}

\begin{abstract}
THE TAUA SMEAR ZONE, STATE OF CEARA: SENSE OF SHEAR, STIMATED DISPLACEMENT, STRUCTURAL EVOLUTION, AND ASSOCIATED GRANITOGENESIS. The Taua shear zone (TSZ) comprises a subverlical minylonitic belt more than $5 \mathrm{~km}$ wide whose development marks the transition from a tangencial to a transcurrent tectonics at the end of the Braziliano (Pan-African) Cycle. Numerous kinematic indicators point to a sinistral sense of shear, with a stimated 30 to $35 \mathrm{~km}$ of horizontal displacement. The main features of the TSZ are interpreted as resulting froin progressive deformation. As time evolved, the present level of exposure was carried to successively shallower structural levels, and the deformational regime changed from ductile (plastic deformation of all minerals) to semiductile (beggining of brittle deformation in feldspars; Production of S-C mylonhes) and, then, to semibrittle (cataclasis predominates over dynamic recrystallization; pseudotachylytes are formed). During the mail, stages of deformation, granitic magmas ascendend toward the surface throughout the subvertical foliation of the TSZ. Arriving at the intrusion level they suffered flow differentiation and originated the synteclonic Pedra Lisa granites. During the crystallization of these rocks, deformation continued showing local variations in intensity. When the semibrittle regime was reached high strain areas were localized in narrow shear bands, so preserving the early formed structures. Fine-grained late-tectonic granites were possibly intruded along extension fissures formed at this stage. Brittle faults can represent the continuation of the deformalional history until the brittle regime or result from a late, unrelated, event.
\end{abstract}

Keywords: Transcurrent shear zone, structural evolution, emplacement of granitoids.

\begin{abstract}
RESUMO A zona de cisalhamento Tauá (ZCT) compreende uma faixa milonítica subvertical com mais de 5 $\mathrm{km}$ de largura cuja evolução teve início no final do Ciclo Brasiliano, marcando a passagem de uma tectônica tangencial para uma tectônica transcorrente. Numerosos indicadores cinemáticos apontam um sentido sinistral para o cisalhamento, com um rejeito estimado de 30 a $35 \mathrm{~km}$. As principais feições da ZCT são interpretadas como produtos de deformação progressiva. Com o tempo, o presente nível de exposição foi levado a níveis crustais cada vez mais rasos, passando de um regime dúctil (todos os minerais deformam-se plasticamente) para semidúctil (início cie deformação frágil nos feldspatos: produção de milonitos S-C) e, daí, para semifrágil (predomínio de cataclase sobre recristalização dinâmica; produção de pseudotaquilitos). Entre o primeiro e o segundo estágio houve a instrusão de magmas graníticos aproveitando a verticalização das estruturas que, ao chegarem à intrusão, sofreram diferenciação por fluxo e originaram os granitóides sintectônicos Pedra Lisa. Após a cristalização dessas rochas, a deformação continuou, a uma taxa decrescente, preservando as estruturas produzidas nos estágios iniciais. Possivelmente aproveitando a formação de fissuras de extensão, quando as encaixantes já tinham um comportamento dúctil-frágil e a deformação mais intensa se restringia a faixas estreitas, houve a intrusão de granitos tardi-tectônicos de granulação fina. Falhas de caráter absolutamente frágil podem representar uma continuação da deformação até o regime rúptil ser atingido ou resultam de um evento tardio.
\end{abstract}

Palavras-chaves: Zona de cisalhamento transcorrente, evolução estrutural, colocação de granitóides.

INTRODUCÃO Zonas de cisalhamento transcorrentes de grande escala usualmente têm um significado tectônico fundamental, em muitos locais limitando terrenos com evolução tectono-metamórfica distinta ou definindo zonas de deformação mais intensa dentro deles (Daly 1987). Um avanço significativo no seu estudo foi o reconhecimento de que processos de deformação plástica são dominantes sobre processos cataclásticos (Sibson 1977, Lister \& Snoke 1984), ou seja, a maioria dos minerais deformam-se ductilmente, gerando milonitos. O principal fator responsável pelo desenvolvimento dessas rochas é o aumento de temperatura com a profundidade, porque processos termalmente ativados, tais como difusão, aceleram os processos plásticos (MainPrince \& Nicolas 1989). Assim, zonas de cisalhamento transcorrentes podem ser consideradas as equivalentes profundas, dissecadas, das grandes falhas de rejeito direcional observadas em níveis estruturais mais rasos (Sibson 1977, Hanmer 1988, Shimamoto 1989).

A Província Borborema, no Nordeste do Brasil, tem como uma de suas principais características o notável desenvolvimento desse tipo de estrutura (Fig. 1), tornando-se impe- rativo um melhor conhecimento de sua natureza para a interpretação da evolução tectônica da região. As zonas de cisalhamento do Nordeste ("lineamentos") foram consideradas por vários autores como falhas antigas, reativadas em diferentes ocasiões e cujo caráter transcorrente registraria um evento tectônico tardio do Ciclo Brasiliano (Almeida et al. 1977, Brito Neves 1975, 1986, Mello et al 1978, Mello 1984). Atualmente, elas estão sendo reinterpretadas como estruturas produzidas apenas no final desse ciclo tectônico (Arthaud 1986, Arthaud \& Torquato 1989, Arthaud \& Caby 1990), e a natureza dominantemente dúctil da maioria daquelas estudadas um pouco mais det alhadamente está plenamente estabelecida. No entanto, os estudos mais recentes têm se concentrado na descrição de feições de escala local ou, no espectro oposto, conduzidos para reconhecimento, sendo poucos os casos onde um mapeamento sistemático das faixas miloníticas tenha sido realizado.

Visando dar uma contribuição nesse sentido, este trabalho enfocará a zona de cisalhamento Tauá, uma das principais transcorrências dúcteis do Estado do Ceará, analisando sua relação com a tectônica dos terrenos adjacentes, descrevendo 


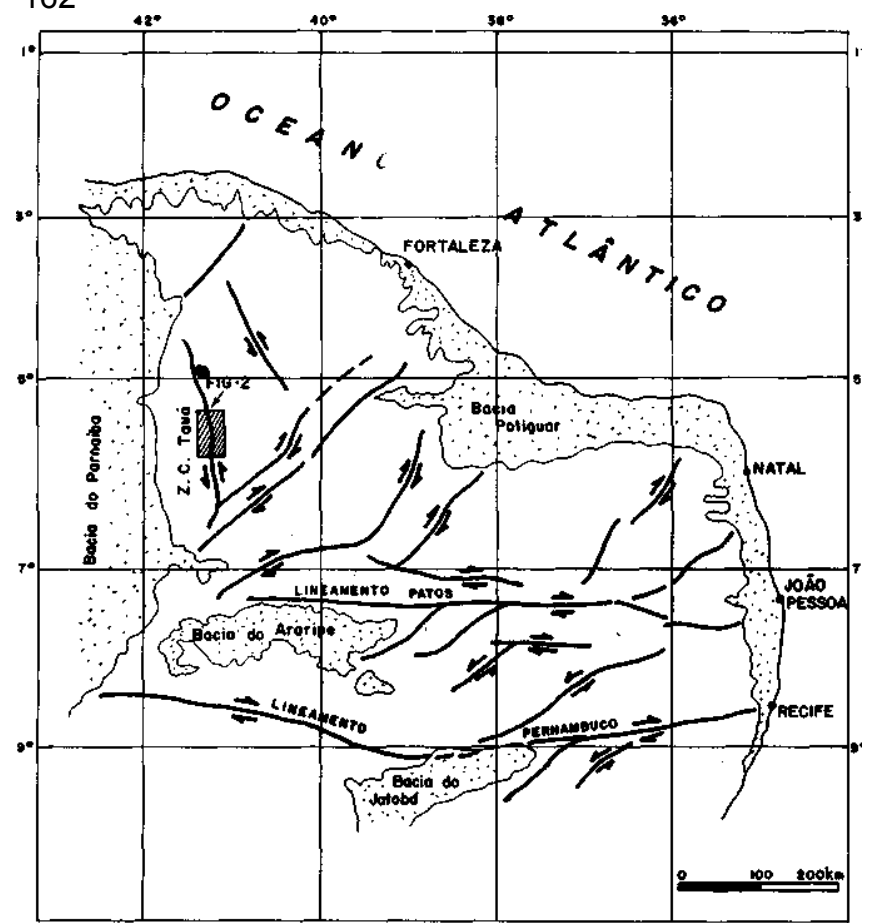

Figura 1 - As principais zonas de cisalhainento transcorren tes do nordeste oriental, com localização da área estudada Figure 1- The main transcurrent shear zones of eastern Northeast, with location of the studied área

os critérios utilizados na determinação do sentido de cisalhamento, dando uma estimativa do deslocamento através dela e analisando seu papel na intrusão e diferenciação de granitóides. Finalmente, a partir da integração dos dados discutidos nos itens precedentes, será apresentado um sumário de sua evolução estrutural com o decorrer do tempo.

SITUAÇÃO GEOLÓGICA GERAL A zona de cisaIhamento Tauá (ZCT) estende-se em uma direção aproximada NNW no oeste do Estado do Ceará (Fig. 1). A área estudada, abrangendo toda porção oeste da Folha Independência (SB. 24-V-D-I, Fig. 2), tem como encaixantes, a leste, paragnaisses diversos, xistos e quartzitos, com ocorrências localizadas de mármores e rochas cálcio-silicáticas, metamorfizados na fácies anfibolito, que gradam a migmatitos para o norte. Arthaud et al (1988) agruparam estas rochas, anteriormente subdivididas em várias unidades, no "Complexo Ceará", atribuindo ao mesmo idade brasiliana. Nos mapas regionais (Gomes et al. 1981, Cavalcante 1983), os migmatitos aparecem como unidade mais antiga; porém, os dados de campo suportam as interpretações de Arthaud \& Hartmann (1986) e Arthaud et al. (1988) de origem por fusão parcial dos metassedimentos durante metamorfismo progressivo. Pequenos stocks graníticos são encontrados em associação com os migmatitos (Fig. 2) e podem exibir transição gradual para os mesmos, sugerindo derivação por fusão parcial e homogeneização mais ou menos in situ do mesmo material metassedimentar (Winkler 1976). São constituídos de biotita granitos de coloração avermelhada, granulação média a grossa, localmente porfiríticos, com megacristais de feldspato potássico que podem atingir até $10 \mathrm{~cm}$ de comprimento, e têm composições variando de álcali-feldspato granito a sienogranito (nomenclatura conforme Streckeisen 1976). Além destes, ainda ocorre na área mapeada, próximo à cidade de Independência (Fig. 2), um granito que apresenta foliação gnáissica, localmente migmatizado, devendo portanto ser pré- a sintectônico à deformação e metamorfismo das encaixantes.

A oeste da zona de cisalhamento dominam migmatitos, gnaisses tonalíticos e graníticos (possivelmente ortoderiva- dos) e anfíbolitos (comumente granatíferos). Essas rochas foram agrupadas por Gomes et al (1981) no "Complexo Nordestino", ao qual atribuíram idade pré-cambriana inferior a média. Embora não existam evidências diretas da relação temporal entre essa unidade e as rochas a leste da ZCT, seu padrão estrutural mais complexo sugere para ela evolução tectônica anterior à do "Complexo Ceará". De fato, os dobramentos isoclinais frequentes, as transposições do bandamento e os padrões de redobramento coaxial ocasionalmente encontrados contrastam fortemente com as estruturas presentes a leste, onde padrões mais complexos são encontrados apenas na proximidade de zonas de empurrão (onde dobras apertadas com eixos curvos são comuns) e da zona de cisalhamento Tauá. Em geral, no entanto, as rochas a leste têm estrutura bastante simples, apresentando foliação com direção afetada por dobramentos abertos e suaves, variando de NNW a NNE, e mergulhos de moderados a baixos. Apesar dessas diferenças litológicas e estruturais, localmente são observados xistos de alto grau e migmatitos no sul da Folha Independência, especialmente nas proximidades do Açude Jaburu (Fig. 2), petrograficamente bastante semelhantes aos encontrados no nordeste da área.

Sheets graníticos estão presentes ao longo de quase todo o comprimento da ZCT e apresentam contatos aproximadamente paralelos aos limites da zona de cisalhamento. Essas rochas usualmente têm foliação de fluxo que, em vários locais, é superimposta por foliação milonítica. Elas correspondem ao ortognaisse de Crateús, de Tagliani \& Gomes (1988) e Tagliani et al (1988), ou aos granitóides Pedra Lisa, de Neves (1989). Diques aplíticos e pegmatíticos, alguns dos quais mapeáveis, podem estar associados com elas. Além dessas, são encontrados ainda granitos (s.s.) de granulação fina que parecem representar a atividade granítica tardia relacionada com a zona de cisalhamento.

O último evento magmático registrado na área é a ocorrência, a nordeste, de diques ácidos a intermediários, orientados segundo a direção NW-SE (Fig. 2), e de pequenos diques de diabásio, sem direção preferencial. Nenhum desses corpos apresenta foliação tectônica; para os primeiros, uma idade cambriana é admitida (Almeida et al. 1984, Almeida 1988), enquanto os segundos devem ser de idade juro-cretácica (Gomes et al 1981).

\section{A ZONA DE CISALHAMENTO TAUÁ Geometria}

Em geral, as margens de zonas de cisalhamento naturais são muito mal definidas porque, próximo a elas, o strain cisalhante é baixo. Para contornar esta dificuldade, os contatos da ZCT assinalados na figura 2 foram colocados por integração, a partir de fotografias aéreas, dos diferentes pontos, onde, no campo, foi identificada a primeira foliação milonítica. Por esse critério, a largura da zona de cisalhamento é de 5 a $6 \mathrm{~km}$, embora os efeitos de uma deformação cisalhante possam ser notados um pouco além dos contatos, como as inflexões da foliação regional, no nordeste da área, e a presença de uma forte lineação de estiramento nos paragnaisses, na porção centro-sul.

Deve-se ressaltar que nem todas as rochas presentes no interior da ZCT são milonitos. Além dos granitóides, pods de rochas quase não deformadas pelo síram cisalhante são também comuns (Fig. 2). Os protólitos dos milonitos são muito variáveis, mas migmatitos estromáticos são dominantes.

A distribuição da deformação no interior da ZCT é extremamente heterogénea, não havendo um aumento contínuo do strain cisalhante em direção ao centro, como no caso de zonas de cisalhamento teóricas. Regiões de baixo e alto strain podem ser encontradas lado-a-lado, mesmo na escala de afloramento, sendo possível observar em vários locais a coexistência de protomilonitos, milonitos e ultramilonitos. As regiões de alto strain são caracterizadas por faixas de ultramilonitos, com algumas dezenas de metros de largura, aproximadamente paralelas aos bordos da zona. Nos demais locais, a foliação 


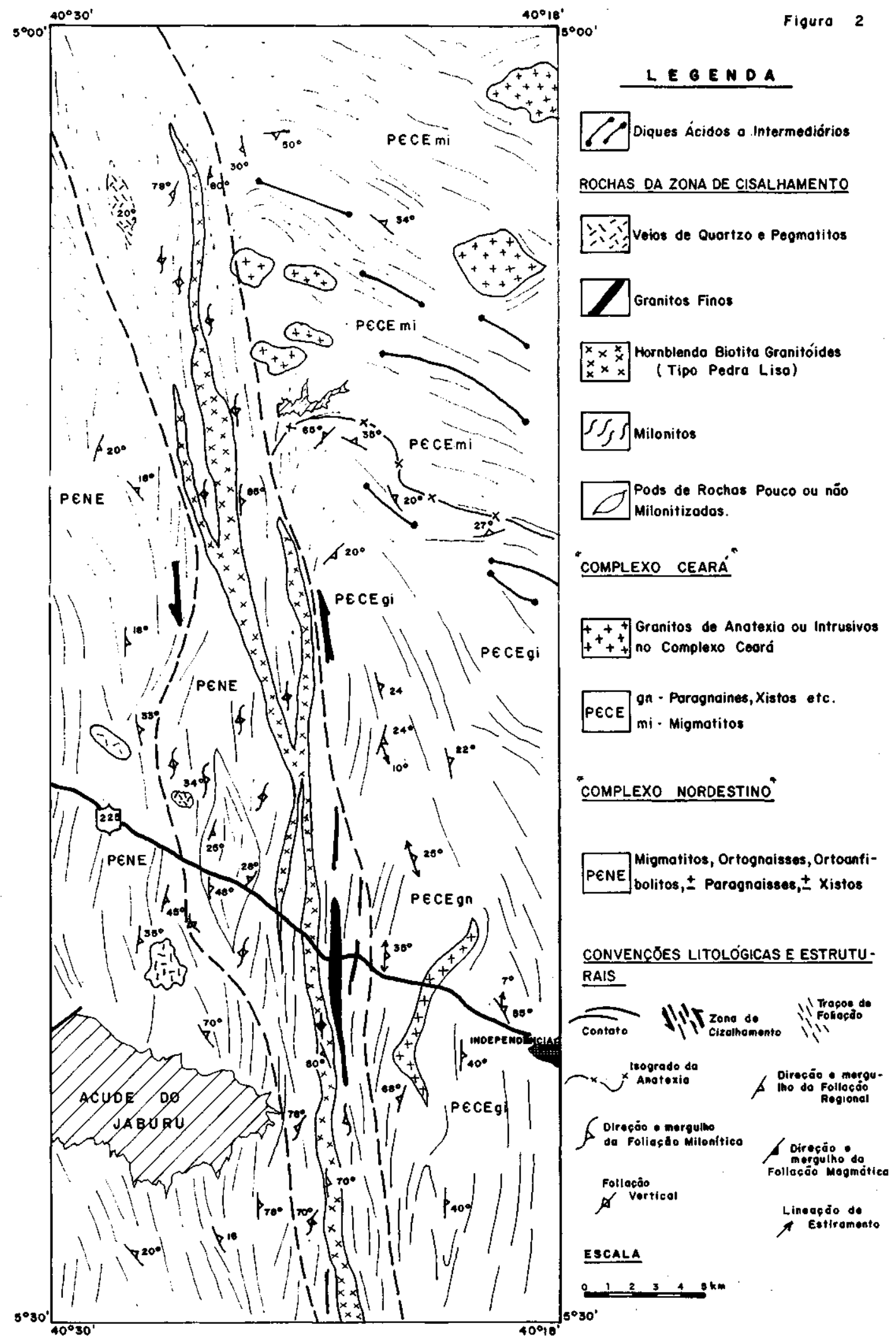

Figura 2 - Mapa geológico simplificado da porção oeste da Folha Independência, mostrando a distribuição das rochas no interior da zona de cisalhamento Tauá. (Para maior clareza, muitos dados foram omitidos. Cópias do mapa original, na escala 1:100.000, podem ser obtidas com o autor)

Figure 2 - Simplified geological map of the west part of Independência sheet, showing the distribution of rocks in the interior of Tauá shear zone. (For clartiy, several data ommited. Copies of the original map, in the 1:100,000 Scale, may be obtained from the author) 
usualmente faz um ângulo de $10^{\circ}$ a $20^{\circ}$, no sentido anti-horário, com estes.

Excetuando os locais de baixo strain, a foliação milonítica é subvertical a vertical, mergulhando de $70^{\circ}$ a $90^{\circ}$, ora para leste ora para oeste, contrastando com os valores médios a baixos encontrados para a foliação nas rochas regionais. Uma lineação de estiramento é usualmente observada e, em alguns locais, uma trama $\mathrm{L}$ é melhor desenvolvida que a trama planar S. Isto é particularmente válido para rochas que originalmente não possuíam forte anisotropia planar, como anfibolitos e granitos.

Como a natureza dos protólitos e a intensidade de deformação são variáveis, o aspecto petrográfico dos milonitos também varia, mas uma marcada redução na granulação é característica comum a todos eles. Usualmente, uma aparência bandada é distintiva, definida por bandas de coloração clara e escura alternadas, de espessura mili- a centimétrica, provavelmente refletindo heterogeneidades composicionais originais. A foliação milonítica $\left(\mathrm{S}_{\mathrm{m}}\right)$ é paralela ao bandamento e definida pela orientação preferencial de porfiroclastos de feldspatos e minerais da matriz recristalizados. Agregados lineares de quartzo em $\mathrm{S}_{\mathrm{m}}$ definem a lineação milonítica.

Relação temporal com a tectônica do "Complexo Ceará" Um modelo bastante aceito para zonas de cisaIhamentos transcorrentes é aquele em que elas aluariam como rampas laterais para cinturões de empurrão. Como o "Complexo Ceará" é interpretado como resultante de uma tectônica tangencial (Arthaud \& Hartmann 1986, Arthaud et al. 1988), a ZCT poderia ser interpretada como uma rampa lateral para ele. Porém, os cisalliamentos de baixo ângulo presentes nessa unidade possuem indicadores cinemáticos que consistentemente indicam um transporte de material de norte para sul. Caso a ZCT fosse uma rampa lateral desses empurrões, seu movimento deveria ser dextral, enquanto todos os critérios cinemáticos, discutidos a seguir, mostram que ela é uma transcorrência sinistral. Isto significa que a tectônica tangencial e a tectônica transcorrente não são, pelo menos em boa parte, eventos contemporâneos. Por outro lado, nenhuma evidência foi encontrada sugerindo que outro tipo de movimento tenha precedido o funcionamento da ZCT como uma transcorrência. Assumindo, para o "Complexo Ceará", uma idade proterozóica superior, a ZCT deve representar o último evento tectônico intenso que afetou a região no final do Ciclo Brasiliano.

O caráter tardio da ZCT é testado pelas seguintes evidências: 1. a foliação regional é infletida nas proximidades da zona de cisalhamento; 2. um dos granitos anatéticos do "Complexo Ceará", truncado pela ZCT (Fig. 2), é não-foliado e quase isotrópico no exterior da zona, sendo convertido para um milonito com forte anisotropia planar no seu interior; 3 . os granitóides sintectônicos à ZCT contêm xenólitos de gnaisses interpretados como pertencentes ao "Complexo Ceará" em virtude de seu caráter aluminoso.

Metamorfismo Associações minerais estáveis mostram que os milonitos formaram-se sob condições do fácies anfibolito. Metapelitos e paragnaisses milonitizados têm a associação plagioclásio-feldspato potássico-quartzo-granada, e anfibolitos milonitizados apresentam a associação plagioclásio-hornblenda-clinopiroxênio-quartzo-granada. A estabilidade das paragêneses minerais formadas durante o metamorfísmo regional indicam que a temperatura permaneceu relativamente elevada após o pico metamórfico responsável pela formação dos migmatitos do "Complexo Ceará", sugerindo que o início da deformação cisalhante não deve ter sido muito delongado após a estruturação dessa unidade. O retrometamorfismo é apenas localizado e inclui a desestabilização de granada para epídoto e zoisita, hornblenda para biotita, epídoto e titanita, biotita para epídoto e, mais raramente, muscovita e opacos.
Sentido de cisalhamento Uma série de estruturas, observáveis desde a escala macroscópica até a escala microscópica, fornecem, de forma consistente, um deslocamento sinistral para a ZCT. O caráter sinistral da transcorrência foi reconhecido por Arthaud (1986) com base na observação de algumas dessas estruturas; porém, esta é a primeira vez que um levantamento det alhado de todas elas é apresentado.

OBSERVAÇÕES MACROSCÓPICAS Os limites da ZCT têm direção aproximada N10W. Observações em fotografias aéreas combinadas com estudos de campo das rochas regionais mostram que a foliação externa é deíletida nas suas proximidades, gradualmente mudando em direção e mergulho, e indicando sentido de cisalliamento sinistral (Fig. 2).

Por outro lado, a foliação milonítica interna tem direção que varia de N10W a N10E, fazendo obliquidade com os limites da zona que também é consonante com o movimento sinistral.

ESTRUTURAS MESOSCÓPICAS Muitas das estruturas presentes em milonitos e úteis na determinação do sentido de cisalliamento podem ser encontradas na zona de cisalhamento Tauá.

Porfiroclastos assimétricos (Simpson \& Schmid 1983, Passchier \& Simpson 1986) são comuns nas porções graníticas de migmatitos milonitizados e em granitóides porfiríticos deformados, pré- ou sintectônicos ao funcionamento da zona de cisalhamento (Fotos 1 e 2). Porfiroclastos do tipo ô são dominantes, mas porfiroclastos do tipo a são também comuns. Um levantamento da população de porfiroclastos em todos os afloramentos onde eles estão presentes indica estatisticamente um movimento anti-horário. A variação na geometria dos cristais deve resultar, em parte, da forma original do grão (porfiroclastos do tipo õ desenvolvem-se mais facilmente a partir de cristais equidimensionais) e, em parte, refletir flutuações na razão entre a taxa de recristalização (R) e a taxa de deformação (y). (Passchier \& Simpson 1986, Mawer 1987).

Pull-aparts assimétricos (Hanmer 1986) são observados em todas as rochas que apresentam camadas com competências contrastantes. Em migmatitos milonitizados seu desenvolvimento é controlado pela espessura das bandas graníticas (Foto 3) - quando esta são finas, estruturas extensionais estão ausentes ou são mal desenvolvidas, mas, acima de $4 \mathrm{~cm}$, a individualização de swells é clara. O sentido de cisalhamento (anti-horário, sem exceção) é indicado pelo ângulo agudo entre o comprimento do swell (ou sua anisotropia interna) e a foliação externa ou pelas terminações assimétricas nas suas extremidades (Foto 3 ). Em granitóides deformados, a mesma situação é mostrada por cumulados de feldspatos ocasionalmente encontrados (Fotos 4), xenólitos de anfibolito (Foto 5), e diques pegmatíticos (Foto 6). Nos diques de pegmatito boudinados, cada boudin está limitado por cisalhamentos discretos e que fornecem um movimento sinistral (Foto 6). Esta última estrutura corresponde à boudinage do tipo III descrita por Goldstein (1988). Ainda em granitóides é comum a ocorrência de estruturas S/C (Berthé et al 1979, Foto 1).

Foliation fishes (Hanmer 1986), um caso particular do tipo 2A de pull-aparts assimétricos, são usualmente encontrados em migmatitos milonitizados; consistem de volumes lenticulares (pods) de segmentos de foliação inclinados de $10^{\circ}$ a $15^{\circ}$ para a foliação externa. $\mathrm{O}$ ângulo agudo entre as duas foliações sempre indica um cisalhamento sinistral (Foto 7). Estas estruturas são equivalentes, em uma escala menor, à boudinage de foliação (foliation boudinage, Lacassin 1988) vista na escala de mapa (Fig. 2) e que também fornece um movimento sinistral.

Dobras assimétricas são comuns na zona de cisalhamento. Elas geralmente são estritamente isoclinais, têm planos axiais paralelos ou inclinados de um pequeno ângulo para a foliação 

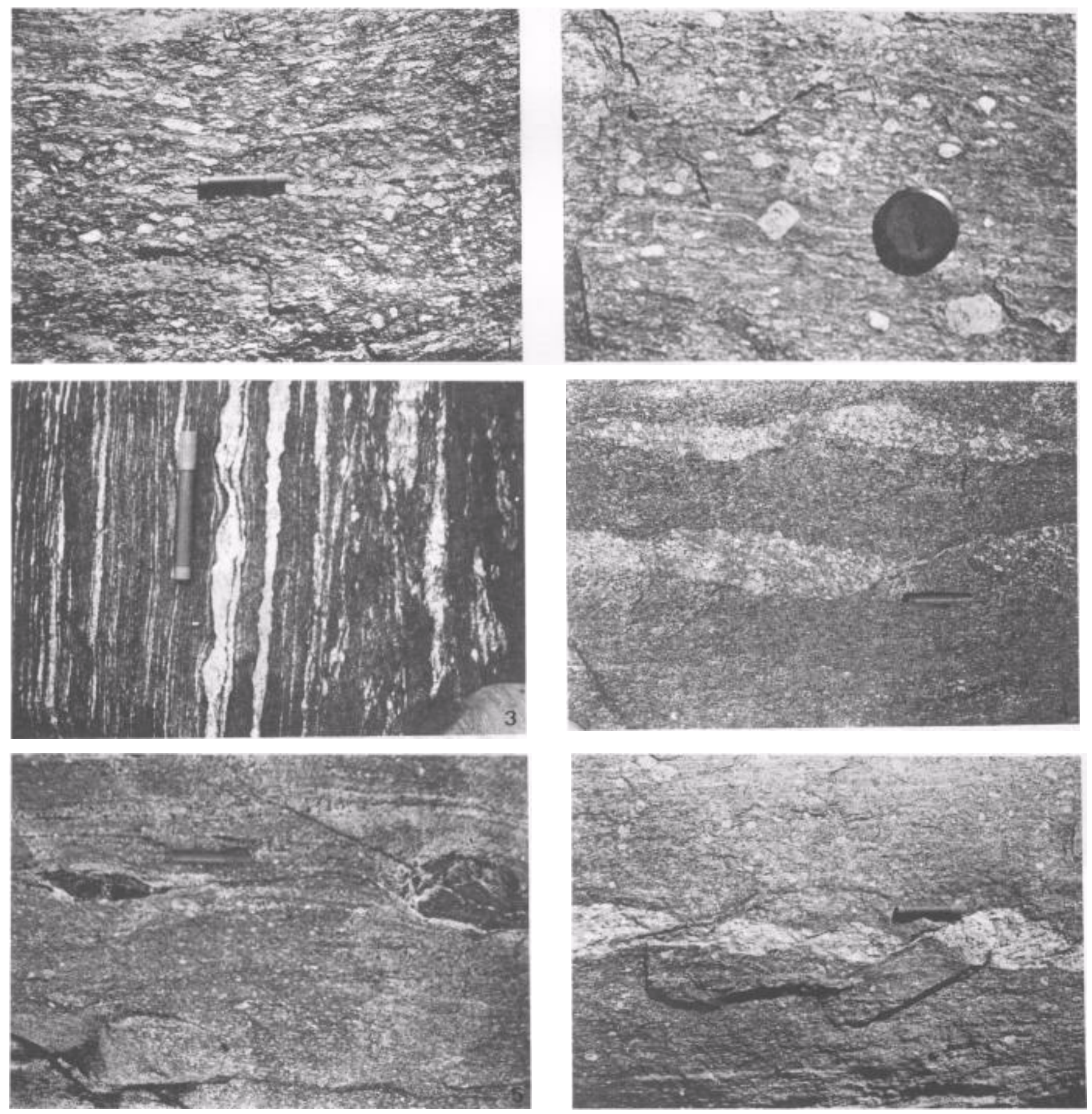

Pranclia 1-1. Granito porfirílico pré-cisalhamenlo milonitizado. Fora da zona de cisalhamento ele é não-deformado e quase isotrópico. A assimetria dos porfiroclastos e relações $S$-C (Indo superior direito) indicam movimento sinistral; 2 . Granito porfirítico sintectônico (tipo Pedra Lisa) milonitizado. Porfiroclastos assimétricos indicam cisalhainento sinistral; 3 . Migmatito milonitizado mostrando pinch-and-swells assimétricos em nm nível granítico; 4. Pull-aparts assimétricos em cumulados de plagioclásio em granitóide sintectônico (Pedra Lisa); 5. Xenólitos de anfibolito em granitóide sintectônico (Pedra Lisa) boudinados assimetricamente; 6. Dique de pegmatito estirado e bondinado assimetricamente em granitóide sintectônico (Pedra Lisa). O norte situa-se à direita na foto 2. Nas demais ilustrações, a escala (comprimento aproximado: $15 \mathrm{~cm}$ ) aponta para o norte

Plate 1 - 1. Pretectonic mylonitic porpliyritic granite. Outside the shear zone it is undeformed and almost isotropic. Sinistral movement shown by tlie asyninietry of porpliyroclasls and S-C structures (top right); 2. Sintectonic niylonitic porphyritic granite (Pedra Lisa type). Asymlnetrical porphyroclasts show sinistral shear; 3. Mylonilic migmatHe showing asymlnetrical pinch-and-swells in a granitic band (center); 4. Asymmetric pull-aparts in plagioclase cumulates in sintectonic granitoid (Pedra Lisa); 5. Ampliibolite xenolith in smtectonic granitoid (Pedra Lisa) showing asyrnmetric boudinage; 6. Asymmetrically bouclinagecl pegmatite dike in sintectonic granitoid (Pedra Lisa). North to the right in photo 2. In ali others the scale (measuring approxinately $15 \mathrm{~cm}$ ) points the norlh 
milonítica e eixos subverticais. Em muitos locais apresentam uma assimetria $\mathrm{S}$, indicando cisalhamento sinistral (Foto 8). $\mathrm{O}$ uso dessas estruturas como indicadores cinemáticos não é muito seguro quando tomados isoladamente devido aos complexos padrões de dobramento exibidos pelas litologias a oeste da zona de cisalhamento, tomando problemática a distinção entre dobras realmente sin-miloníticas e dobras preexistentes rotacionadas. Por isso, não é incomum encontrar-se dobras com assimetria Z. No entanto, quando usadas em conjunto com os outros critérios descritos, permitem uma inferência razoável de um sistemático sentido de assimetria sinistral.

Zonas de cisalhamento dúcteis discretas são ocasionalmente observadas recortando a foliação milonítica. Cisalhamentos sinistrals são mais comuns (Foto 9), mas cisalhamentos dextrais também ocorrem (Foto 10). No primeiro caso, a maioria tem. direção N10 a N20W e são mais comuns na proximidade de faixas ultramiloníticas, podendo ser interpretadas, com confiança, como cisalhamentos C (Bertlié et al. 1979), desenvolvidos paralelamente à direção do movimento. Outros cisalhamentos sinistrals, oblíquos em até $45^{\circ}$ com respeito aos limites da ZCT, podem ser interpretados como cisalhamentos RI, correspondendo à clivagem de crenulação extensional de Platt \& Vissers (1980) ou às bandas de cisalhamento de White (1979) e Harris \& Cobbold (1984). Um único cisalhamento sinistral com direção N30E pode representar um cisalhamento $\mathrm{P}$, que geralmente não é frequente, seja em milonitos naturais ou produzidos experimentalmente (Sliimamoto 1989). Os ci-
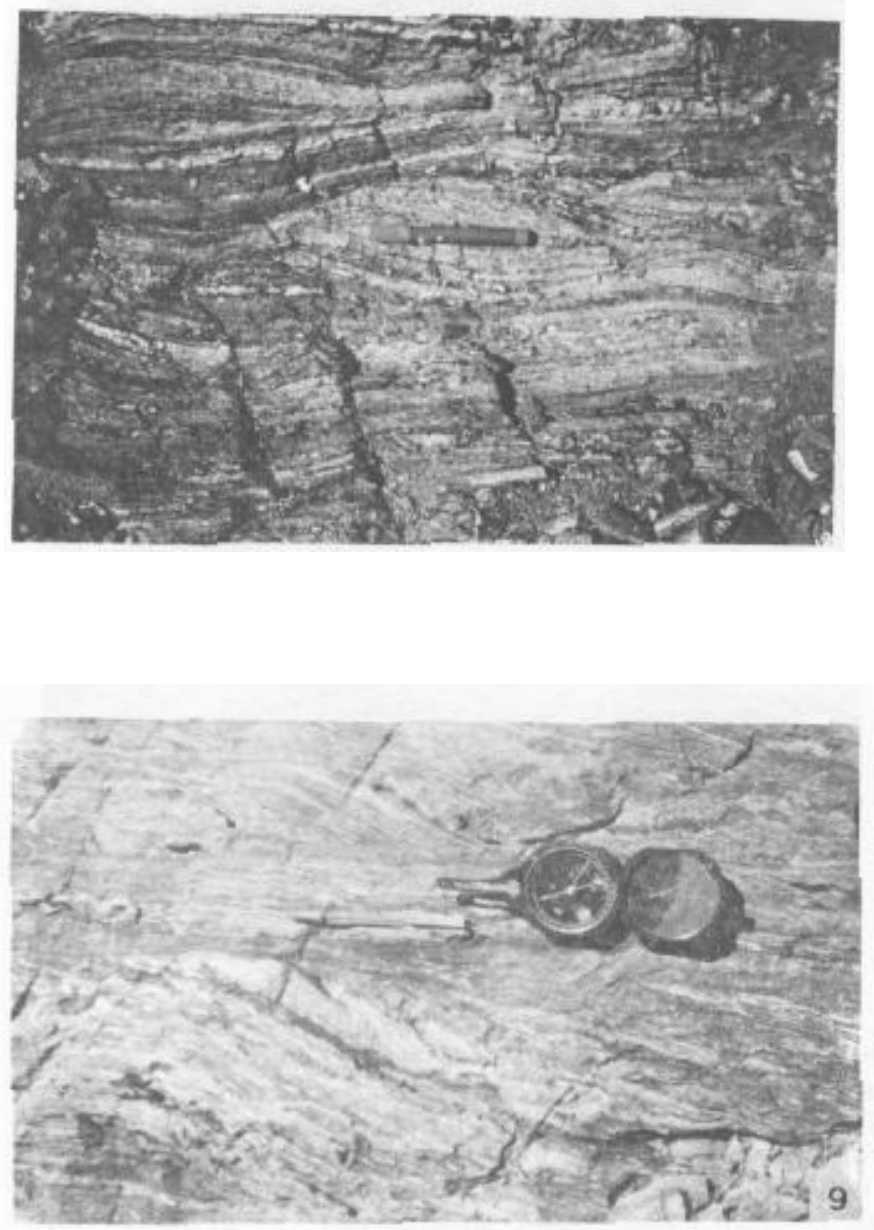

salhamentos dextrais têm direção N15 a N45E e fazem ângulos de 30 a $40^{\circ} \mathrm{com}$ a foliação milonítica, similar aos encontrados em clivagens de crenulação extensionais antitéticas descritas em outras regiões (Harris \& Cobbold 1984, Behermann 1987). Dados de campo e estudos experimentais demonstram que cisalliamentos sintéticos e antitéticos podem ser produzidos ao mesmo tempo durante deformação não-coaxial (Harris \& Cobbold 1984, Shimamoto 1989) e, assim, os cisalhamento dextrais são compatíveis com o movimento sinistral global.

Outros indicadores cincmáticos são menos frequentes, mas também indicam movimento sinistral. Estes incluem fissuras de extensão sigmoidais com fornia de $\mathrm{S}$, preenchidas por quartzo ou material pegmatítico, e fraturas sintéticas e antitéticas em megacristais de feldspatos. Além destas, outras feições desenvolvidas em granitóides sintectônicos durante o fluxo magmático, descritos adiante, também corroboram o movimento anti-horário.

MICROESTRUTURAS Muitas das estruturas descritas acima são observadas também em escala microscópica (porfiroclastos assimétricos, cristais fraturados e deslocados etc.), enquanto outras são vistas exclusivamente nessa escala. Exemplos são os porfiroclastos do tipo 0 (Hooper \& Hatcher 1989) presentes em ultramilonitos, ribbons de quartzo microdobrados assimetricamente e mica fislics (Lister \& Snoke 1984).

Estimativa do deslocamento $\mathrm{Na}$ ausência de marcadores litológicos distintivos que pudessem ser relacionados

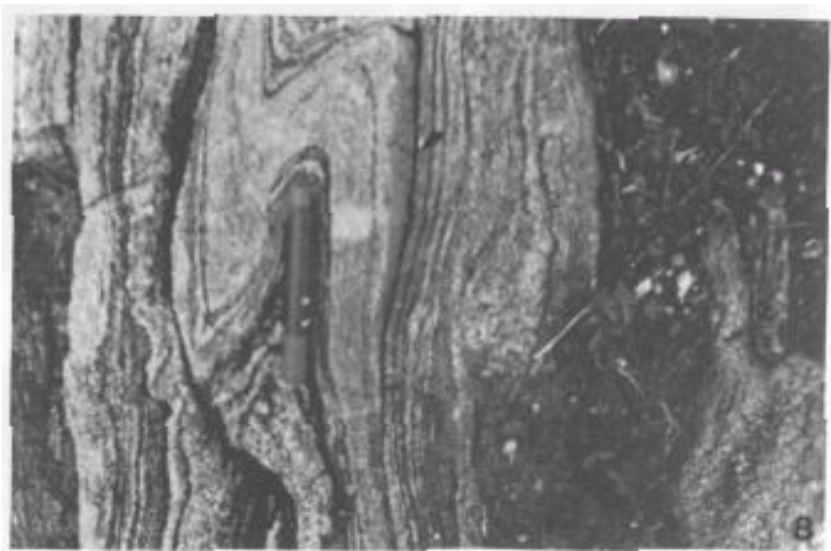

Prancha 2-7. Foliation fish em migmatito milonitizado indicando movimento sinistral; 8. Dobras com assimetria $S$ em migmatito milonitizado indicando cisalhamento sinistral; 9 e 10. Cisalhamentos sinistral e dextral com direções aproximadas $N-S$ e N40E, respectivamente. A haste da bússola aponta o norte

Plate 2-7. Foliation fish ia mylonitic migmatite indicating sinistral movement; 8. Asymmetrical S-folds in mylonitic migmatite sl.owing sinistral n.oveme.it; 9 and 10. Sinistral and dextral shears trei.ding N-S and NE-SW, respectively. The compass spindle points to the north 
através da zona de cisalhamento (diques, por exemplo), o deslocamento horizontal na ZCT foi estimado determinando-se: 1. a rotação da foliação regional com respeito aos limites da zona, e 2. a obliquidade entre estes e a foliação milonítica interna. As limitações dos dois métodos são bem conhecidas e serão discutidas após a apresentação dos resultados.

$\mathrm{O}$ primeiro método consistiu em medir o ângulo inicial a entre a foliação preexistente e o plano de cisalhamento (considerado paralelo aos limites da zona) e os valores sucessivos tomados pelo ângulo $\alpha$ ', quando ela é progressivamente encurvada à medida que se aproxima do limite da zona. $\mathrm{O}$ cálculo foi restrito apenas ao nordeste da área, onde o traço da foliação e seu progressivo encurtamento é claramente visível em fotografias aéreas, permitindo maior precisão nas medidas. Assume-se, portanto, que o deslocamento calculado representa metade do deslocamento total. O strain cisalhante $(\gamma)$ está relacionado a $\alpha$ e $\alpha$ ' pela fórmula (Ramsay 1967):

$\gamma=\operatorname{cotg} \alpha^{\prime}-\operatorname{cotg} \alpha$

e o deslocamento total D é dado por (Ramsay \& Granam

1970):

\section{$\mathrm{D}=2 \int_{0}^{x} \gamma \mathrm{dx}$}

onde $\mathrm{x}$ é a distância entre o limite da zona de cisalhamento e a posição inicial onde a foliação parece ser defletida para o plano de cisalliamento. Com esta convenção, pode-se antecipar que os resultados darão apenas uma estimativa mínima do deslocamento porque a integração dos valores deveria ser conduzida até o centro da zona de cisalhamento. Isto não foi possível devido à total obliteração da foliação preexistente pela superimposição da foliação milonítica. Valores de D foram calculados para cinco seções (Fig. 3) e variaram de 3.000 a $6.000 \mathrm{~m}$ (Tab. 1).

No interior da zona de cisalhamento, foi empregado o método da tangente, que consiste em medir os diferentes valores de 6 ' entre a foliação milonítica e o plano de cisalhamento. O strain cisalhante está relacionado a 6 pela fórmula (Ramsay \& Graliam 1970):

$\operatorname{tg} 20^{\prime}=2 / \gamma$

e o deslocamento total é novamente

\section{$\mathrm{D}=\int_{a}^{*} y \mathrm{dx}$}

onde agora x é a largura da zona de cisalhamento. Valores de D foram calculados para dez seções (Fig. 3) e variaram de 20.800 a $59.100 \mathrm{~m}$ (Tab. 1).

Como seria de se esperar, pela razão exposta anteriormente, o primeiro método fornece valores bastante inferiores aos obtidos pelo segundo. Como os segmentos de foliação encurvados efetivamente já fazem parte da zona de cisalhamento, embora não tenham sido assim considerados neste trabalho (vide seção Geometria), a adição dos resultados fornecidos pêlos dois métodos na estimativa do deslocamento total é justificável. Um rejeito mínimo de $24 \mathrm{~km}$ e máximo de 65 $\mathrm{km}$ é obtido com esse procedimento. Observa-se uma ampla dispersão de valores: porém, com um maior acúmulo de dados na faixa de 30 a $40 \mathrm{~km}$.

Várias razões podem ser responsáveis pelas discrepâncias das medidas nas diferentes seções. Em primeiro lugar, o deslocamento não é necessariamente constante para diferentes segmentos de uma mesma zona de cisalhamento. Em segundo, a ZCT não se ajusta a uma zona de cisalhamento teórica, onde baixos valores de strain são encontrados próximos às margens e valores máximos concentram-se na região central. Em terceiro, implícito na aplicação dos métodos, estão os pressupostos de que a deformação resulta de cisalhamento simples

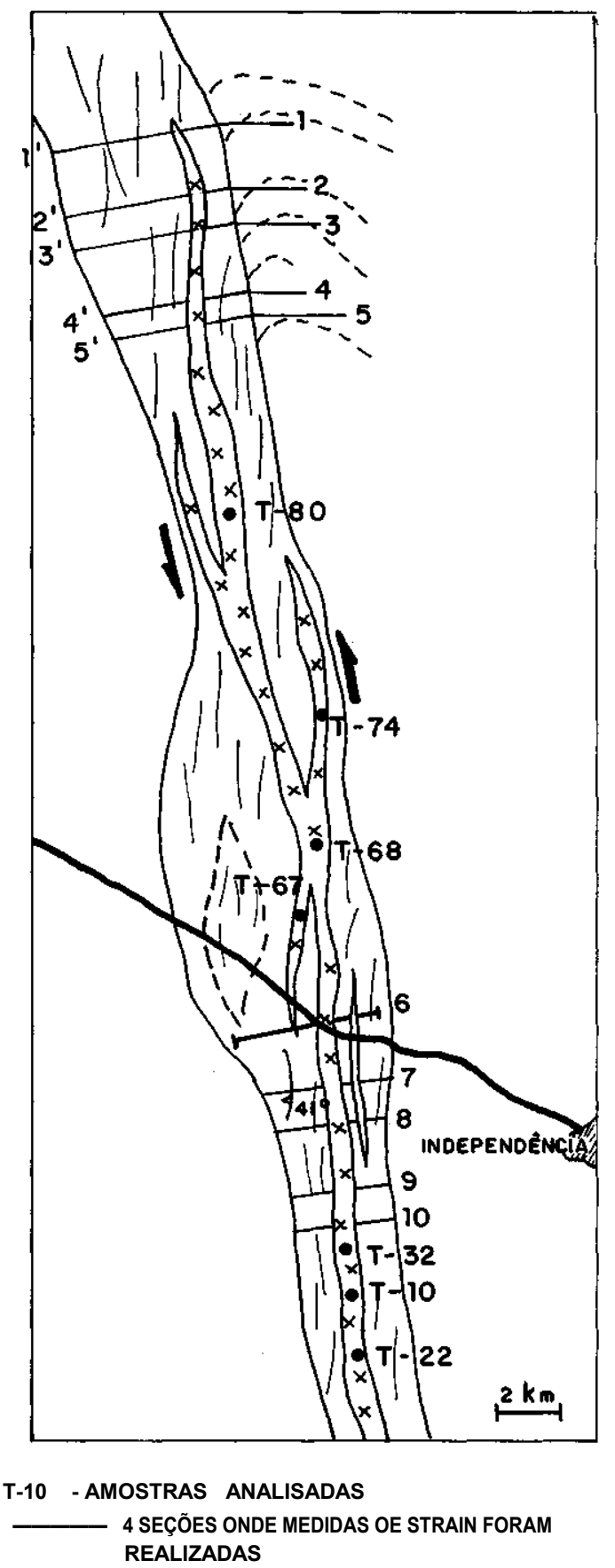

Figura 3 - Mapa mostrando as seções onde foram realizadas medidas de strain (Tab. 1) e a localização das amostras cujas composições modais foram determinadas (Tab. 2)

Figure 3 - Map showing the sections along which strain measurements have been made (Tab. 1) and the location of samples whose modal compositions have been determined (Tab. 2)

com volume constante e que não ocorrem descontinuidades através da zona. Apesar da ultima condição parecer aplicar-se, porque nenhuma falha importante foi detectada, as duas primeiras não são bem satisfeitas, como será visto na próxima seção. Por fim, a deformação cisalhante foi superimposta em rochas previamente deformadas, tornando difícil separar o strain devido a cada um dos eventos. Assim, os deslocamentos calculados para algumas seções podem ter sido superestimados, porque estruturas inclinadas de baixo ângulo para a direção do cisalhamento podem ter sido exageradas durante a deformação cisalhante.

Apesar dessas limitações, um deslocamento da ordem de $30 \mathrm{a} 35 \mathrm{~km}$, ou seja, inferior à média dos valores máximo e 
Tabela 1 - Deslocamento ao longo da zona de cisalhamento Tauá calculado a partir de fotografias aéreas (escala 1:25.000)

Table 1 - Displacement along the Tauá Shear Zone calculated from aereal photos (1:25,000 scale)

\begin{tabular}{c|c|c|c}
\hline \multicolumn{2}{c|}{ Primeiro Método $\left(\alpha^{\prime}\right)$} & \multicolumn{2}{c}{ Segundo Método $\left(\theta^{\prime}\right)$} \\
\hline Seção & $\mathrm{D} / 2(\mathrm{~m})$ & Seção & $\mathrm{D}(\mathrm{m})$ \\
\hline 1 & 1508 & $1^{\prime}$ & 41.606 \\
\hline 2 & 2631 & $2^{\prime}$ & 26.413 \\
\hline 3 & 2851 & $3^{\prime}$ & 31.890 \\
\hline 4 & 2981 & $4^{\prime}$ & 35.714 \\
\hline 5 & 3084 & $5^{\prime}$ & 29.134 \\
\hline & & 6 & 24.031 \\
\hline & & 7 & 20.777 \\
\hline & & 8 & 59.073 \\
\hline & & 9 & 36.572 \\
\hline & & 10 & 38.919 \\
\hline
\end{tabular}

mínimo para balancear o strain preexistente, parece razoável, em vista das similaridades litológicas encontradas a SW e a $\mathrm{NE}$ da ZCT. Isto poderá ser confirmado pêlos estudos adicionais a sul da Folha Independência e é compatível com a correlação positiva entre deslocamento (D) e espessura (T) compilada para várias zonas miloníticas mundiais por Hull (1988). Para estas, a razão D/T variou de 1 a 10 . Como a ZCT tem 5 a $6 \mathrm{~km}$ de largura, o deslocamento sugerido cai dentro desse intervalo $(\mathrm{D} / \mathrm{T}=5$ para $\mathrm{D}=30 \mathrm{kmeT}=6 \mathrm{~km}$; $\mathrm{D} / \mathrm{T}=7$ para $\mathrm{D}=35 \mathrm{kmeT}=5 \mathrm{~km})$.

Mecanismo de deformação As estruturas assimétricas presentes no interior da ZCT mostram que o regime de deformação foi não-coaxial. Um funcionamento em transtração, embora próximo a uma deformação plana, foi proposto por Arthaud (1986) e Tagliani et al. (1988), Neves (1989), com dilatação normal às paredes da zona, acomodando a intrusão dos granitóides sintectônicos. Segundo Sanderson \& Marchüii (1984), zonas transtrativas são caracterizadas por elipsóides de strain prolatos $(\mathrm{k}>1)$ e, efetivamente, na ZCT observa-se um predomínio da trama L sobre a trama $\mathrm{S}$ em rochas que originalmente não possuíam uma forte anisotropia planar, reforçando essa interpretação.

AS ROCHAS GRANÍTICAS Dois tipos de granitóides foram reconhecidos na área estudada (Neves 1989): um inequigranular, relativamente grosso, localmente porfirítico, e cornposicionalmente variado; e um de granulação fina e composição restrita. O primeiro tipo corresponde ao ortognaisse de Cratéus de Tagliani \& Gomes (1988) ou aos granitóides Pedra Lisa de Neves (1989), e sua textura e composição mineralógica foram descritas por esses autores.

Granitóide Pedra Lisa CAUSAS DA VARIAÇÃO COMPOSICIONAL Composições modais, representativas dessas rochas, e a distribuição espacial das amostras são apresentadas na tabela 2 e na figura 3, respectivamente. Nessas análises, os teores de hornblenda estão subestimados, porque locais onde ocorrem concentrações desse mineral foram evitados. De modo geral, observa-se, de sul para norte, aumento progressivo das razões quartzo/feldspatos, feldspato potássico/plagioclásio, e biotita/hornblenda. Neves (1989) atribuiu essa variação composicional ao fracionamento de hornblenda e possivelmente também de plagioclásio (agora comprovado pela descoberta de cumulados desse mineral, Foto 4) pelo mecanismo de diferenciação por fluxo. Pelo modelo proposto
(Fig. 4), o magma granítico começaria a ascender na porção centro-sul da área até atingir um nível onde o contraste de densidade com as encaixantes não permitisse mais sua subida. A partir daí, ele começaria a se deslocar horizontalmente, induzido em parte pelo movimento horizontal dos blocos nos lados opostos da zona de cisalhamento e em parte pela pressão exercida à proporção que novos pulsos magmáticos chegaram ao nível de intrusão. A principal evidência para um movimento horizontal do magma é o paralelismo entre a lineação magmática e a lineação milonítica.

Além da separação de cristais e líquido durante o fluxo horizontal, outros fatores podem ter contribuído para a variabilidade composicional. Assim, é bastante provável que mistura de magmas mais e menos diferenciados tenha ocorrido, embora os encraves microgranulares presentes nessas rochas não possam ser tomados como evidências petrográficas desse processo, porque magmas com composições semelhantes devem se misturar prontamente (Vernon et al 1988).

Os encraves mais provavelmente representam cumulados cognatos, porções cristalizadas precocemente durante a história de intrusão, desmembradas e reincorporadas, durante o fluxo magmático (Wall et al 1987). Sua interpretação como restitos (Chappell et al 1987) é inviável, porque restitos devem apresentar textura granoblástica e composições empobrecidas em sílica e álcalis, o que não é o caso (Neves 1989). Alguns encraves devem ter servido como sítios favoráveis à nucleação de cristais, sendo comum encontrar-se encraves orlados por cristais de hornblenda (Foto 11). Isto os protegeria de interações posteriores com o magma, enquanto aqueles encraves, possivelmente um pouco mais jovens, que não foram capazes de desenvolver uma carapaça protetora, tornaram-se sujeitos a modificações posteriores devido à elevação de temperatura causada pela chegada de magmas menos diferenciados ao nível de intrusão. É possível, assim, encontrar-se encraves em vários estágios de assimilação (Fotos 12 e 13).

Xenólitos das rochas encaixantes também devem ter tido um papel na modificação da composição do magma. A maioria desses xenólitos são de migmatitos com vários metros de comprimento por alguns decímetros de largura, frequentemente apresentando injeções de material granítico novo ao longo do bandamento. Suas grandes dimensões e disposição espacial orientada sugerem transporte por distâncias relativamente curtas. O magma granítico ao passar através deles sofreria localmente rebaixamento de temperatura, acelerando sua taxa de cristalização. Esse efeito, porém, deve ser de importância limitada em relação ao progressivo aquecimento sofrido pêlos xenólitos, eventualmente podendo-se atingir temperatura suficiente para fundir a porção neossomática dessas inclusões, enriquecendo o magma em componentes félsicos.

$\mathrm{O}$ aumento de viscosidade resultante da assimilação parcial dos xenólitos pode ter sido compensado pela assimilação de água das encaixantes, proveniente da desestabilização de minerais hidratados. Para situações correspondentes à porção mediana da crosta, muscovita deve começar a desidratar-se a temperaturas inferiores a $700^{\circ} \mathrm{C}$ (Hyndman 1981). A evidência da assimilação pelo magma da água liberada provém do fato dos paragnaisses do "Complexo Ceará" geralmente conterem muscovita em quantidades elevadas (vários \%), enquanto os xenólitos dessas rochas nos granitóides Pedra Lisa são tipicamente ricos em biotita com relação à muscovita.

Em resumo, considera-se que separação de cristais e líquido durante o fluxo magmático, mistura de magmas mais e menos diferenciados, reabsorção de porções cristalizadas precocemente, e assimilação parcial de xenólitos, são os fatores responsáveis pela variabilidade composicional dos granitóides Pedra Lisa, sendo que o primeiro processo é predominante.

ESTRUTURAS Os granitóides Pedra Lisa exibem ampla variedade de estruturas, desde aquelas produzidas durante $\mathrm{o}$ 


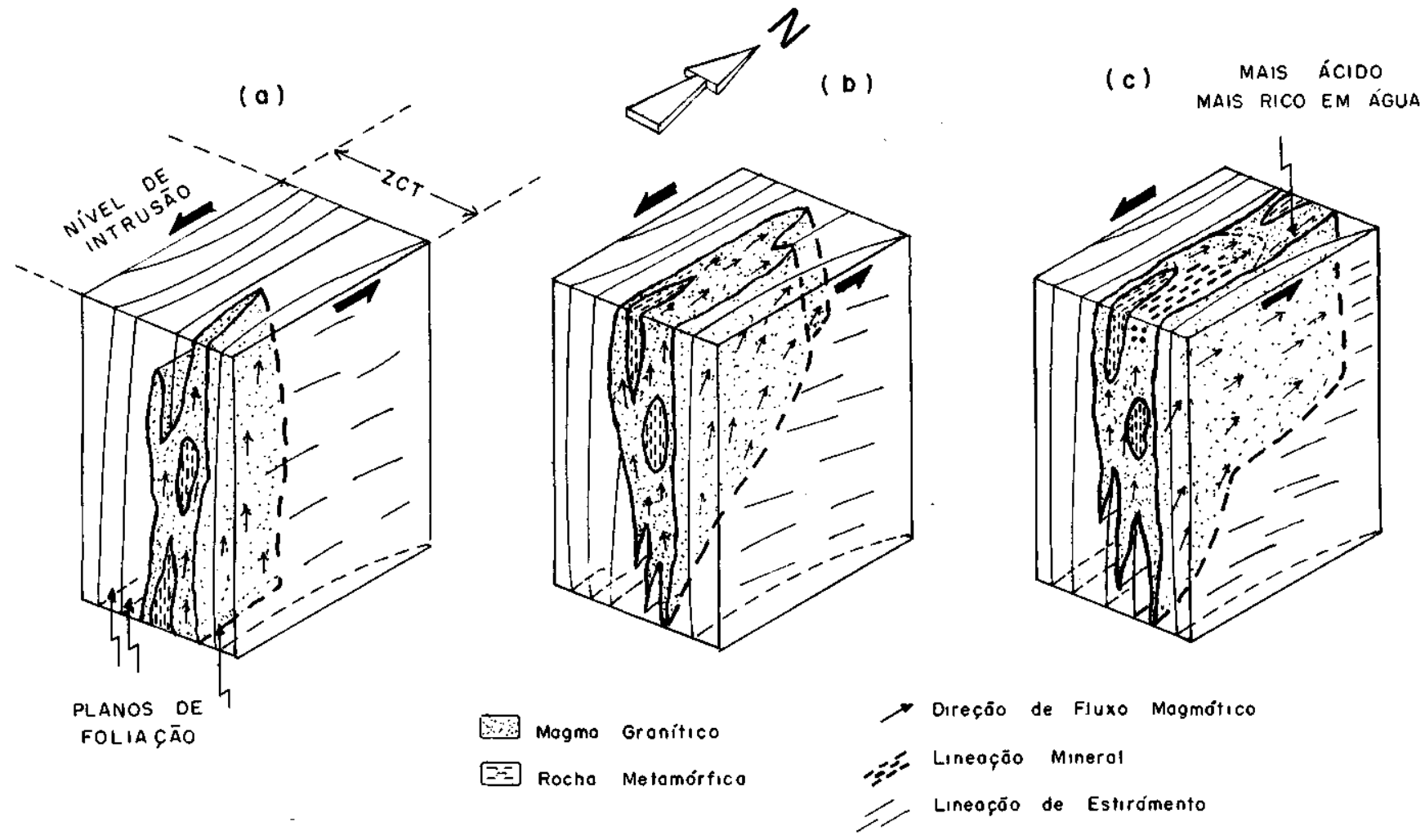

Figura 4 - Modelo proposto para a intrusão e diferenciação dos granitóides Pedra Lisa. a. o magma começa a ascender em direção à superficie aproveitando a verticalização das estruturas na ZCT; $b$. a ascensão do magma é impedida quando o contraste de densidade com as rochas sobrejacentes não permite a continuação do movimento e ele começa a se deslocar horizontalmente; c. durante o fluxo horizontal, os cristais inicialmente formados de hornblenda e plagioclásio são fracionados pelo mecanismo de diferenciação por fluxo (Neves 1989)

Figure 4 - Proposed ascent and differentiation model to the Pedra Lisa granitoids. a. the magma begins its ascent toward the surface throughout the subvertical foliation in the TSZ; b. the density contrast with the overlying rocks hinders the continuous rise of the magma and it begins to flow horizontally; c. during the horizontal flow the early formed hornblende and plagioclase crystals are fractionated by flow differentiation (Neves 1989)

Tabela 2 - Composições modais dos granitóides Pedra Lisa (em \%)

Table 2 - Modal composilions of Pedra Lisa granitoids (\%)

\begin{tabular}{|c|c|c|c|c|c|c|c|c|}
\hline AMO & $\mathrm{T}-22$ & $T-10$ & $\mathrm{~T}-32$ & $\mathrm{~T}-41$ & $T-67$ & $\mathrm{~T}-68$ & T-74 & T-80 \\
\hline Plagioclásio & 46,3 & 50,3 & 43,1 & 57,9 & 46,5 & 39,3 & 33,0 & 36,3 \\
\hline Felc & & & & & & & & \\
\hline Polás & 9,7 & 14,7 & 21,9 & 17,9 & 25,1 & 19,8 & 29,5 & 18 \\
\hline Quartzo & 15,4 & 17,0 & 13,0 & 10,7 & 19,0 & 30,1 & 29,1 & 28,0 \\
\hline Hornble & 5 , & 5,6 & 13,3 & 0,8 & - & - & 3,8 & - \\
\hline Biotita & 19,4 & 11,5 & $6, \overline{6}$ & 10,5 & 9,2 & 10,7 & 3,2 & 15, \\
\hline Outr & 2,7 & 0,8 & 2,1 & $\overline{2,2}$ & 0,2 & 0,1 & 1,4 & 1,6 \\
\hline & & & & & & & & \\
\hline
\end{tabular}

fluxo magmático até aquelas resultantes de deformação no estado sólido. A foliação magmática é definida de forma menos clara que os planos de foliação em rochas metamórficas; mas, geralmente, é possível definir-se estatisticamente uma orientação preferencial média. Para evitar imprecisões, as atitudes da foliação magmática foram tomadas preferencialmente em afloramentos onde ela está exposta em planos de fraturas transversais à sua direção e em locais onde deformação plástica não é muito evidente. A maioria dos planos medidos são subverticais e têm direção que variam de N10W a N07E.

Em regime de fluxo não-coaxial, a orientação preferencial dos cristais em um magma injetado em zona de cisalhamento ativa é oblíqua ao plano de cisalhamento e esta obliquidade indica o sentido do movimento (Fernandez 1987, Blumenfeld \& Bouchez 1988, MainPrice \& Nicolas 1989). A assimetria da foliação magmática nos contatos dos granitóides Pedra Lisa, orientados mais a noroeste que esta (Fig. 2), indica, portanto, que estas rochas foram intrudidas quando a $\mathrm{ZCT}$ ainda estava em funcionamento e que o seu sentido era sinistrai, ou seja, como sua cinemática é a mesma da zona de cisalhamento, elas são rochas sintectônicas. Indicadores cinemáticos de fluxo, como a ligeira obliquidade entre os encraves microgranulares e a orientação preferencial da matriz e o entelhamento ou imbricamento (tuilage, Blumenfeld 1983) de megacristais de feldspato potássico, também confirmam o deslocamento sinistral.

A foliação magmática é definida pela disposição planar de cristais tabulares de feldspatos, prismas de hornblenda e palhetas de biotita. Nas porções onde a deformação no estado sólido não é evidente à vista desarmada, quartzo ocorre em agregados anedrais não alinhados ou intersticialmente aos cristais orientados de biotita e hornblenda; extinção ondulante e bandas de deformação estão presentes nesse mineral, mas não há evidências de recristalizaçao, atestando apenas incipiente deformação no estado sólido.

A passagem da deformação durante o fluxo magmático para deformação no estado sólido aparentemente foi contínua, como indicado pela produção de agregados de quartzo elipsóidais orientados paralelamente à estrutura magmática, pela recristalizaçao dos feldspatos, e pelo aparecimento de pertitas em cristais de feldspato potássico recristalizados. Estas fei- 
ções indicam deformação a temperaturas elevadas, próxima ao solidus do granito (Guinebarteau et al 1987, Paterson et al 1989).

Nas porções mais deformadas, a foliação milonítica é dada pelo estiramento e recristalização de grãos de quartzo e biotita e por porfiroclastos assimétricos de feldspatos (Foto 14). A foliação magmática é quase totalmente obliterada pelo crescente paralelismo entre as superfícies S e C (Tagliani \& Gomes 1988), mas o componente magmático do fluxo pode ser inferido pela preservação de faces cristalinas em alguns grãos de feldspatos e pelo paralelismo entre o comprimento maior dos clastos de plagioclásio e suas lamelas de geminação (Paterson et al 1989).

A intensidade da deformação no estado sólido parece ter sido basicamente uma função da composição mineralógica local, refletindo a proporção relativa de minerais frágeis para minerais dúcteis (Vemon \& Flood 1988). De fato, na porção sul da área, onde plagioclásio e hornblenda são abundantes, deformação plástica mais intensa se restringe a zonas de cisalhamento discretas (Foto 15); enquanto para o norte, devido ao aumento da proporção de quartzo e biotita, a deformação é pervasiva (Foto 14).

Diques aplíticos e pegmatíticos são comumente encontrados em associação com os granitóides Pedra Lisa, especialmente nas porções mais félsicas. Relações de truncamento mostram que eles são de várias geracões (Foto 16). Seu cará ter co-magmático é atestado pelo sutil início a partir da matriz granítica e pelo fato de os megacristais de feldspato não serem truncados pelas paredes dos diques (Hibbard 1980, Hibbard \& Waters 1985). Em regiões pouco deformadas, eles podem ter qualquer orientação (Foto 16), o que provavelmente resulta da liberação de fluidos em diferentes estágios de cristalização (Hibbard 1980), mas em regiões mais deformadas são rotacionados e tendem a adquirir uni paralelismo com a foliação milonítica.

Granitos finos Granitos de granulação fina ocorrem como pequenos corpos tabulares ligeiramente discordantes com a foliação das encaixantes (Fig. 2). Relações de truncamento e encraves de granitóides grossos mostram que eles são tardios em relação aos granitóides Pedra Lisa. Petrograficamente, apresentam textura granular xenomórfíca, com cristais de quartzo (predominante), albita e microclínio formando uma matriz na qual se destacam cristais maiores de plagioclásio, alguns dos quais zonados (xenocristais?). Biotita e muscovita ocorrem em quantidades inferiores a 10\%. Em muitos casos, esta última claramente resulta da alteração de feldspatos ou biotita, mas, em outros, parece ser primária, sugerindo cristalização a pressões superiores a 2 ou, mais comumente, a 3 kbar (assumindo condições de saturação em $\mathrm{H}_{2} \mathrm{O}$; Burnham \& Nakvasil 1986. Chatterjee \& Johannes 1974 , Hyndman 1981. Isso indica que a granulação fina é mais uma consequência de rápido resfriamento devido ao pequeno volume dos corpos do que intrusão em níveis crustais rasos.

Muitas amostras dos granitos finos são isotrópicas, não apresentando evidências de deformação, seja no estado magmático ou sólido. Em outras, uma foliação é bem definida, sendo dominante foliação magmática, porque os grãos da maioria dos minerais não apresentam evidências de deformação plástica intensa. Nestas, certo bandamento composicional e granulométrico é observado, com níveis mais finos, ricos em quartzo e biotita, alternando-se com níveis quartzo-feldspáticos mais espessos. Faixas ultramiloníticas são formadas aproveitando essas descontinuidades, quando as amostras apresentam-se deformadas, com quartzo e biotita sendo estirados paralelamente à foliação principal. Esta deformação se dá ainda dentro do campo dúctil, o que resulta, na maior parte, da grande ductibilidade desses minerais e da granulação fina da rocha, mas, de qualquer maneira, mostra que o nível de intrusão não pode ter sido muito raso, caso contrário, processos cataclásticos seriam dominantes (Handy 1989).

EVOLUÇÃO ESTRUTURAL DA ZCT As estruturas presentes na zona de cisalhamento Tauá registram uma prolongada história deformacional. Ela foi ativa antes, durante e após a intrusão e cristalização das rochas graníticas, e as condições deformacionais abarcam desde um comportamento totalmente dúctil até outro completamente frágil das rochas, embora até o momento tenham-se enfatizado os processos de deformação plástica por serem estes os mais marcantes.

A julgar pelo que ocorre com falhas rúpteis (Mandl 1987, Hanmer 1989) ou com zonas de cisalhamento dúcteis de pequenas dimensões (Simpson 1983), no início do desenvolvimento da ZCT, a deformação cisalhante deve ter se concentrado em domínios estreitos, formando zonas de cisalhamento pouco espessas, com o mesmo sentido de deslocamento, que se interligam e envolvem regiões menos deformadas. Pode-se inferir que as regiões mais susceptíveis a serem inicialmente afetadas seriam aquelas onde a foliação preexistente teria uma orientação mais favorável com respeito ao elipsóide de strain local, isto é, situada dentro do campo de estiramento. Deslocamentos subsequentes tenderiam a se concentrar nessas regiões e poderiam rotacionar até atingir um quase paralelismo com o plano de cisalhamento. Com o decorrer da deformação, essas heterogeidades seriam progressivamente acentuadas, envolvendo aquelas regiões originalmente pouco afetadas no processo de milonitização.

As principais características geométricas da ZCT podem ser explicadas pelo modelo acima: as faixas ultramiloníticas corresponderiam aos locais onde a deformação cisalhante teve início e por isso acumularam mais strain, enquanto os pods representariam as porções que resistiram mais à deformação por possuírem uma orientação mais desfavorável. Outros fatores podem ter contribuído para a distribuição extremamente heterogénea da deformação na ZCT, como heterogeneidades reológicas, variações na taxa de strain de local para local etc.; porém, considera-se a orientação da foliação preexistente como o fator preponderante na resposta das rochas ao cisalhamento.

Esta fase inicial ocorreu na fácies anfibolito. Feições mesoe microscópicas mostram que o regime reológico era inteiramente dúctil porque milonitos e ultramilonitos bem foliados são amplamente dominantes sobre milonitos S/C (Lister \& Snoke 1984), considerados as rochas características do regime semidúctil (Shimamoto 1989). A evidência microestrutural reside na extrema plasticidade dos feldspatos, que exibem extinção ondulante, geminados mecânicos, bandas de deformação e extensiva recristalização dinâmica, o que exige temperaturas superiores a $480-500^{\circ} \mathrm{C}$ (Tullis 1983, Capais 1989).

A largura atingida pela zona de cisalhamento na sua maturidade $(5-6 \mathrm{~km})$ é compatível com as condições metamórfica e reológica inferidas, porque, para zonas de cisalhamentos transcorrentes, parece haver uma correlação direta entre profundidade (e conseqüentemente temperatura) e espessura, àquelas desenvolvidas na fácies xisto-verde possuindo tipicamente menos de $3 \mathrm{~km}$ de espessura (Sibson 1977, Hanmer 1988). Assim, é pouco provável que fraturas venham a se formar $e$ servir como condutos para a ascensão de magmas, como é frequentemente invocado (por exemplo, Davies 1982, Castro 1986). Sugere-se, portanto, que o abrandamento das rochas, induzido pelo strain, e a verticalização das estruturas façam com que estes locais sejam os sítios para onde magmas produzidos em profundidade migrem preferencialmente, explicando a associação comum de granitos e zonas de cisalhamento (Hollister \& Crawford 1986). O processo de colocação, no entanto, seria ainda aquele de intrusão forçada, como no caso de diapirismo.

A presença de xenólitos de milonitos em porções pouco deformadas dos granitóides Pedra Lisa mostra que estas 

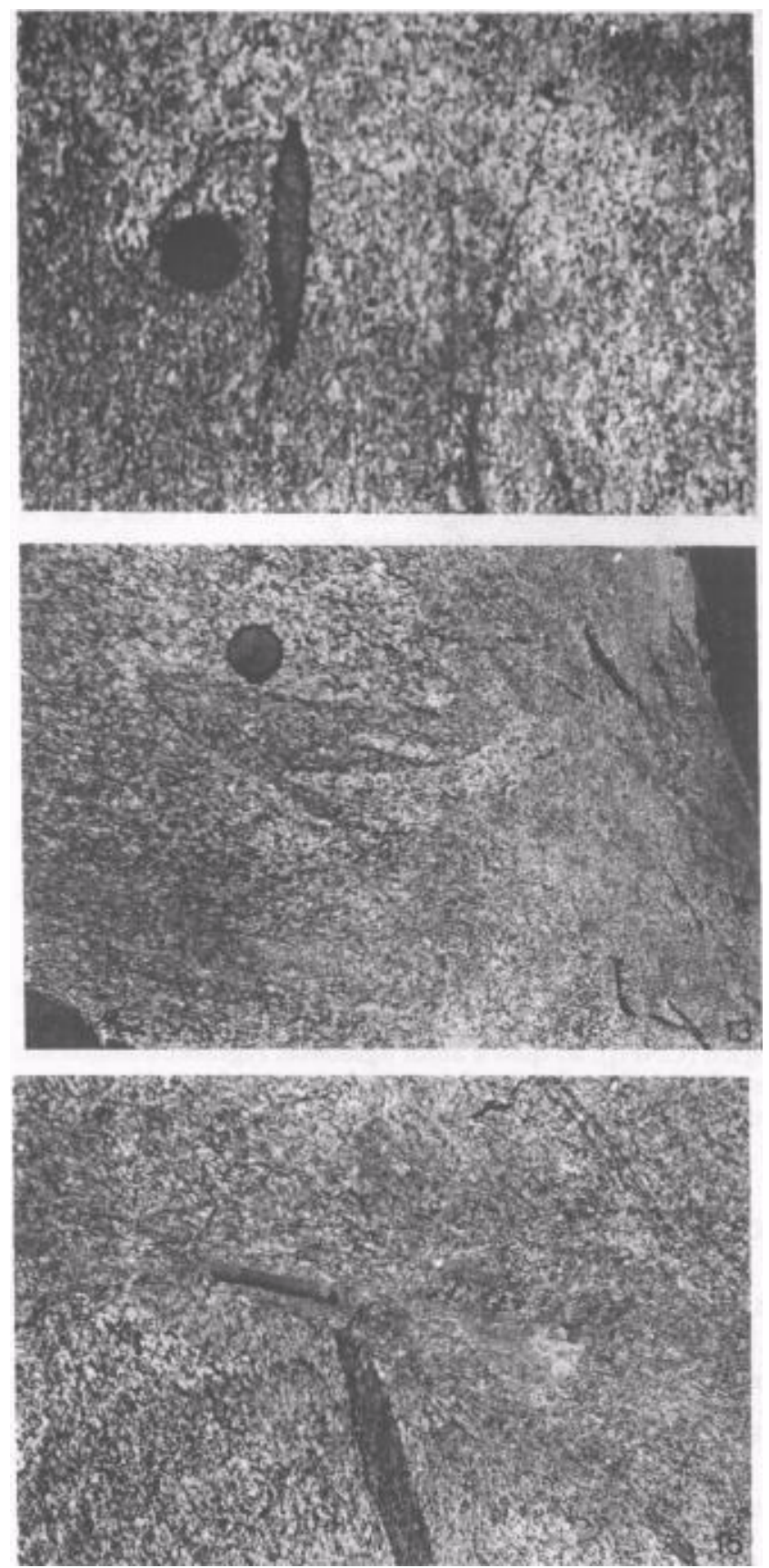
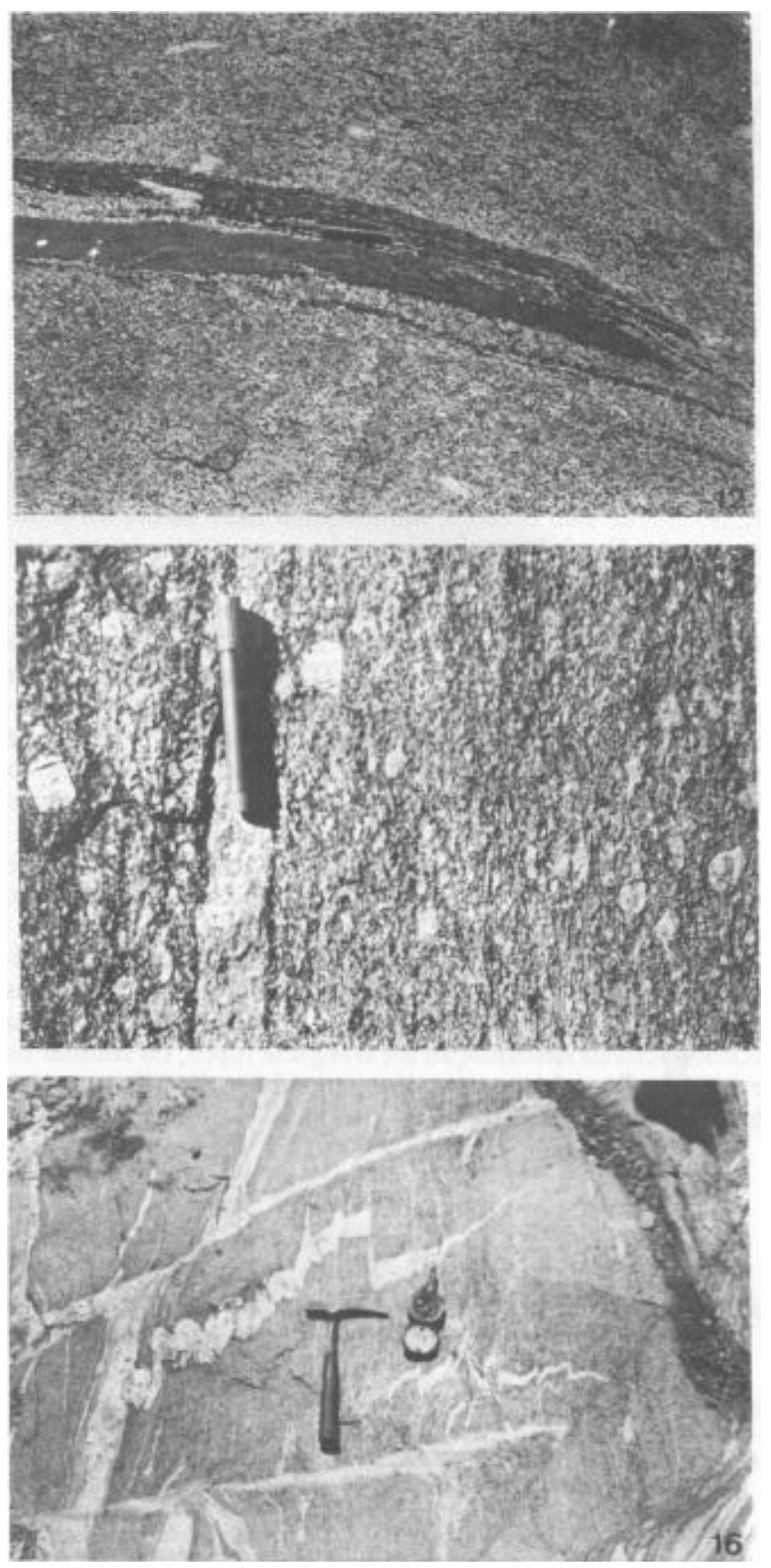

Prancha 3 - 11. Encrave microgranitico orlado por cristais de hornblenda. Notar uma ligeira obliquidade entre o comprimento do encrave e o traço da foliação magmática. Topo da foto para o norte; 12 e 13. Encraves apresentando diferentes estágios de assimilação; 14. Granitóide Pedra Lisa milonitizado. Notar o paralelismo entre a orientação do dique (centro-esquerda) e a foliação milonítica. 15. Granitóide Pedra Lisa com uma foliação magmática bem definida; cortada por cisaUiamento sinistral 16. Diques pegmatíticos com várias orientações no granitóide Pedra Lisa. Notar cisalhamentos antitéticos Plate 3 - 11. Microgranitoid enclave fringecl by hornblende crystals. Note the slight obliquity between the enclave long dimension and the magmatic foliation; 12 and 13. Enclaves at various slages of assimilation; 14. Mylonitic Pedra Lisa gtanitoid. Note the parallelism between the dike (center-left) and the mylonitic foliation; 15. Well-defmed magmatic foliation in Pedra Lisa granitoid transsected by a sinistral skear; 16. Pegmatitic dikes with several orientations in the Pedra Lisa granitoids

rochas foram intrudidas após o início da deformação cisaIhante. Deformação contínua após sua solidificação fez com que eles adquirissem, em parte, uma trama milonítica. A estabilidade de hornblenda, biotita e feldspatos indica que isto se processou ainda na fácies anfibolito. A passagem do regime dúctil para semidúctil (Shimamoto 1989) é indicada pela ocorrência comum nessas rochas de estruturas S/C (Berthé et al. 1989) e de pull-aparts assimétricos (Hanmer 1986,
Goldstein 1988, Fotos 4, 5 e 6). Nas encaixantes, esta transição é marcada pelo início da deformação frágil dos feldspatos em combinação com um alto grau de ductibilidade do quartzo. A formação de zonas de cisalhamento dúcteis discretas também deve estar associada com esta fase. A consistência no sentido de cisalhamento das estruturas produzidas nos estágios dúctil e semidúctil atesta que a cinemática não mudou com o tempo. 
A intrusão dos granitos finos parece ter se dado quando a deformação das encaixantes já evoluía para o regime semi-frágil, porque, apesar deles próprios exibirem, quando deformados, um comportamento dúctil, em alguns locais observa-se sua colocação ao longo de fraturas dilatacionais nos granitóides Pedra Lisa. Zonas de cisalhamento dúcteisfrágeis e fissuras de extensão sigmoidais preenchidas por quartzo seriam as estruturas características deste estágio nas encaixantes. Estas últimas podem ter dimensões variando de poucos centímetros até algumas centenas de metros (Fig. 2) e sua geometria é ainda compatível com deslocamento sinistral. Veios de pseudotaquilito recortando a foliação milonitica também devem ter se formado no final dessa fase.

A orientação dos diques ácidos a intermediários (Fig. 2) é compatível com sua colocação ao longo de tensíon gashes. Se realmente isso ocorreu, indica que a ZCT esteve ativa até o período Cambriano, funcionando continuamente até que níveis crustais bastante rasos fossem atingidos.

Pelas considerações acima, admite-se a manutenção do mesmo regime de deformação crustal durante pelo menos boa parte da história evolutiva da ZCT. Com o tempo, houve progressiva diminuição na intensidade da deformação, preservando as estruturas produzidas nos estágios iniciais de modificações subsequentes. Assim, as principais feições da ZCT podem ser interpretadas como resultantes de deformação progressiva. Como consequência de esfriamento, soerguimento, erosão e consequente descompressão, o presente nível de exposição foi levado a níveis crustais cada vez mais rasos, passando de regime dúctil para semi-frágil.

Falhas métricas a decamétricas, com rejeitos centi a decimétricos são as últimas estruturas registradas na área. Elas têm caráter absolutamente frágil e podem representar uma continuação da deformação até o regime rúptil, ou resultar de evento tardio, talvez mesozóico, quando muitos lineamentos brasilianos foram reativados.
CONCLUSÃO A análise dos dados mega, meso e microestruturais mostra que o desenvolvimento da zona de cisalhamento Tauá foi condicionado pela manutenção de regime de deformação crustal, responsável pelo seu funcionamento como transcorrência sinistral durante boa parte de sua história. Assumindo idade brasiliana para o "Complexo Ceará", o início do cisalhamento deve ter se dado logo após a estruturação dessa unidade, devido à temperatura de formação relativamente elevada inferida para os milonitos. Isto indica que as condições deformacionais vigentes impuseram a mudança de tectônica tangencial para tectônica dominada por movimentos horizontais de blocos no final do Ciclo Brasiliano.

A verticalização das estruturas fez com que a ZCT se tornasse local propício para a intrusão de magmas graníticos que, ao chegarem ao nível de intrusão, foram forçados a fluir horizontalmente, diferenciando pelo mecanismo de diferenciação por fluxo e dando origem aos granitóides Pedra Lisa. A deformação continuou após a cristalização destas rochas, convertendo-as localmente para ortognaisses e milonitos. Com o passar do tempo, a intensidade da deformação foi diminuindo ao mesmo tempo que as condições reológicas mudavam do regime dúctil para semidúctil. Finalmente, a intrusão de granitos finos se dá quando as encaixantes já se comportam de maneira dúctil-frágil e a deformação mais intensa restringe-se agora a faixas estreitas, com pseudotaquilitos sendo gerados quando a tensão acumulada é subitamente liberada.

$\mathrm{O}$ rejeito horizontal estimado para a ZCT (30 a $35 \mathrm{~km})$ deve corresponder em grande parte à fase principal de funcionamento, porque o rejeito ao longo de cisalhamento dúcteis-frágeis é muito pequeno.

Agradecimentos Esta pesquisa foi financiada pelo Conselho Nacional de Desenvolvimento Científico e Tecnológico (CNPq), ao qual o autor agradece. Agradecimentos são devidos ainda a dois revisores anónimos pelas criticas construtivas apresentadas à versão original deste trabalho.

\section{REFERÊNCIAS BIBLIOGRÁFICAS}

ALMEIDA, A.R.; SIAL, A.N.; FERREIRA, V.P. 1984. Petrologia e geoquímica de enxames de diques cambrianos no Nordeste do Brasil. In: SIMP GEOL. NORDESTE, 9. Natal, 1984. Resumo das Comunicações... Natal. SBG.

ALMEIDA, A.R.; SIAL, A.N.; FERREIRA, V.P. 1988. Isótopos de oxigénio em enxames de diques cambrianos do Ceará. Rev.Geol. (UFC), 1:21-30.

ALMEIDA, F.F.M.; HASUI, Y.; BRITO-NEVES, B.B.; FUCK, R.A. 1977. Províncias estruturais brasileiras. In: SIMP. GEOL. NORDESTE, 6. Campina Grande, 1977. Atas .. Campina Grande, SBG p. 363-392.

ARTHAUD, M.H. 1986. A falha de Tauá (CE): zona de cisalhamento dúctil de alto ângulo de rejeito múltiplo. In: CONGR. BRÂS. GEOL., 34. Goiânia, 1986. Anais... Goiânia, SBG. v. 2, p. 766-769.

ARTHAUD, M.H. \& CABY, R. 1990. Petrostructural evolution of Ceará shear zones suggestive of monocyclic. Brasiliano age crustal evolution. In: CONGR. BRAS. GEOL., 36. Natal, 1990. Resumos... Natal, SBG. p. 253 .

ARTHAUD, M.H. \& HARTMANN, M.B. 1986. A geologia da região de Independência (CE): um exemplo de tectônica de nappes no Ceará In: CONGR. BRASS. GEOL., 34. Goiânia, 1986. Anais... Goiânia, SBG. v. 3, Р. 1160-1169.

ARTHAUD, M.H. \& TORQUATO, J.R. 1989. A tectônica transcorrente do Estado do Ceará. In: SIMP. NAC. ESTUDOS TECTÔNICOS, 2. Fortaleza, 1989. Atas... Fortaleza, SBG. p. $277-278$

ARTHAUD, M.H.; HARTMANN, M.B.; TAGLIANI, T.R.M. 1988. Metamorfismo inverso na porção centro-leste da Folha de Independência CE. Suas implicações estruturais e estratigráficas. Rev. Geoi, (UFC), $1: 41-44$

BEHRMANN, J.H. 1987. A precautionary note on shear bands as kinematic indicators. J. Struct. Geol., 9:659-666.

BERTHE, D.; CHOUKROUNE, P.; GAFAIS, D. 1979. Orthogneiss, mylonite and non-axial deformation of granites: the example of the South Arrnorican shear zone. J. Struct. Geol., 1:31-42.

BLUMENFELD, P. 1983. Lê 'tuilage dês mégacristaux', un critère $\mathrm{d}^{*}$ ecoulernent rotationnel pour lês fluidalités dês roches magmatiques. Application au granite de Barbey-Seroux (Vosges-France). Buli. Geol. Fr., 7 Ser., 35:309-318.
BLUMENFELD, P. \& BOUCHEZ, J. 1988. Shear criteria in granite and migmatite deformed in the magmatic and solid states. J. Struct. Geol., 10:361-372.

BRITO-NEVES, B.B. 1975. Regionalização geotectônica do Precambriano nordestino. São Paulo. 198p. (Tese de doutoramento, IG/USP)

BRITO-NEVES, B.B. 1986. Tectonic regimes in the Proterozoic of Brazil. In: SIMP. GEOL. NORDESTE, 12. João Pessoa, 1986. Atas... João Pessoa, SBG. p. 235-251.

BURNHAM, C.W. \& NEKVASIL, H. 1986. Equilibrium properties of granite pegrnatite magmas. Am. Mineral., 71:239-263.

CASTRO, A. 1986. Structural pattern and ascent model in the Central Extremadura batholith, Hercynian belt, Spain. J. Struct. Geol., 8:633-645.

CAVALCANTE, J.C. 1983. Mapa Geológico do Estado do Ceará. Escala 1:500.000. MME/DNPM/CEMINAS.

CHAPPELL, B.W.; WHITE, A.J.R.; WYBORN, D. 1987. The irnportance of residual source material (restite) in granite petrogenesis. J. Petrology, 28:1111-1138.

CHATTERJEE, N.B. \& JOHANNES, W. 1974. Thermal stability and standard thermodynamic properties of synthetic 2Mi-muscovite, $\mathrm{KAl}_{2} \mathrm{Si}_{3} \mathrm{O}_{10}(\mathrm{OH})$. Contrib. Mineral. Petrol., 48:89-114.

DALY, M.C. 1987. Crustal shear zones in Central África: a kinematic approach to Proterozoic tectonics. Episodes, 11:5-11.

DAVIES, F.B. 1982. Pan-African granite intrusion in response to tectonic volume changes in a ductile shear zone from Northern Saudi Arábia. J. Geoi, 90:467-483.

FERNANDEZ, A.N. 1987. Structural petrology and intrusion strain analysis. Rev. Bros. Geoc., 17:372-381.

CAPAIS, D. 1989. Shear structures within deformed granites: mechanical and thermal indicators. Geology, 17:1144-1147.

GOLDSTEIN, A.G. 1988. Factors affecting the kinematic interpretation of asymmetric boudinage in shear zones. J. Struc. GeoL, 10:707-715.

GOMES, J.R.C.; GATTO, C.M.R.P., SOUZA, G.M.C.; LUZ, D.S.; TEIXEIRA, W. 1981. Projeto Radambrasil, Folha SB. 24/25 - Jaguaribe/Natal. Rio de Janeiro, 300p.

GUINEBARTEAU, B; BOUCHEZ, J; VIGNERESSE, J. 1987. The Mortagne granite pluton (France) emplaced by pull-apart along a shear zone: 
structural and gravimetric argumente and regional implications. Geol. Soe. Am. Buli, 99:763-770.

HANDY, M.R. 1989. Deformation regimes and the rheological evolution of fault zones in the lithosphere: the affects of pressure, temperatura, graiiisize and time. Tectonophysics, 163:119-152.

HANMER, S. 1986. Asymmetrical pull-aparts and foliation fish as kinematic indicators. J. Struct. Geol., 8:111-112.

HANMER, S. 1988. Great Slave Lake shear zone, Canadian Shield: reconstrucled vertical ${ }^{\mathrm{p}}$ rofile of a crustal-scale fault zone. Tectonophysics, 149:245-264.

HANMER, S. 1989. Initiation of cataclastic flow in a mylonite zone. J. Struct. Geol., 11:751-762.

HARRIS, L.B. \& COBBOLD, P.R. 1984. Development of conjugate shear bands during bulk simple shearing. J. Struct. Geol, 7:37-44.

HIBBARD, M.J. 1980. Indigenous source of late-stage dikes and veins in granite plutons. Econ.Geol. 75:410-423.

HIBBARD. M.J. \& WATTERS, R.J. 1985. Fracturing and diking in incompletely crystallized granitic plutons. Líhos, 8:1-12.

HOLLISTER. L.S. \& CRAWFORD, M.L. 1986. Melt-enhanced deformation: a major tectonic process. Geology, 14:558-561.

HOOPER, R.J. \& HATCHER, R.D... Jr. 1988. Mylonites from the Towaliga

fault zone. Central Georgia: products of heterogeneous non-coaxial de-

formation. Tectonophysics, 152:1-17.

HULL, J. 1988. Thickness-displacement relationships for deformation zones. J. Struct. Geol., 10:431-435.

HYNDMAN, D.W. 1981. Controls on source and depth of emplacement of granitic magmas. Geology, 9:244-249.

LACASSIN, R. 1988. Large-scale foliation boudinage in gneisses, J. Struct. Geol., 10:643-647.

L1STER, G.S. \& SNOKE, A.W. 1984. S-C mylonites. J. Struct. Geol., 6:617638 .

MANDL, G. 1987. Discontinuous fault zones. J. Struct. Geol., 9:105-110.

MA1NPRICE, D. \& NICOLAS, A. 1989. Development of shape and laltice preferred orientations: applicaüoiis to the seismic anisotropy of the lower crust. J. Struct. Geol., 11:175-189.

MAWER, C.K. 1987. Shear criteria in the Greenville Province, Ontario, Canada. J. Struct. Geol., 9:531-539.

MELLO, A.A. 1984. O padrão de falhamentos do nordeste oriental e algumas tentativas de interpretação. In: CONGR. BRÁS. GEOL., 33. Rio de Janeiro, 1984. Aliais... Rio de Janeiro, SBG. v. 4, D. 1743-1751.

MELLO, A. A.; SOUZA, E.M.; MENDONCA, J.C.G. 1978. A tectônica linear do Estado do Ceará. In: CONGR. BRÁS. GEOL., 30. Recife, 1978. Anais... Recife, SBG. v. 1, ${ }^{\text {p. }}$.393-407.

NEVES, S.P. 1989. Diferenciação de magmas graníticos em zonas de cisalhamento: o caso de Tauá, Ceará. Rev. Bros. Geoc., 19(3):303-309.

PASSCHIER, C.W. \& SIMPSON, C. 1986. Porphyroclast systems as kinematic indicators. J. Struct. Geol., 8:831-843.
PATERSON, S.R.; VERNON, R.H.; TOBISH, C.T. 1989. A review of criteria for the identification of magmatic and tectonic foliaüons in granitoids. J. Struct. Geol., 11:349-363.

PLATT, J.P. \& VISSERS, R.L.M. 1980. Extensional structures in anisotropic rocks. J. Struct. Geol., 2:397-410.

RAMSAY, J. 1967. Folding andfracturing of rocks. New York, McGraw-Hill.

RAMSAY, J. \& GRAHAM, R.H. 1970. Strain variations in shear beíts. Can. J. Earth Sei, 7:786-813.

SANDERSON, D.J. \& MARCHINI, W.R.D. 1984. Transpression. J. Struct. Geol., 6:449-458.

SHIMAMOTO, T. 1989. The origin of S-C mylonites and a new fault zone model. J. Struct. Geol., 11:51-64.

SIBSON, R.H. 1977. Fault rocks and fault mechanism. J. Geol. Soe. London, 133:191-213.

S1MPSON, C. 1983. Strain and shape fabric variations associated with ductile shear zones. J. Struct. Geol., 5:61-72.

SÏMPSON, C. \& SCHM1D, S.M. 1983. An evaluation of criteria to deduce the sense of movement in sheared rocks. Buli. Geol. Soe. Am., 94:12811288.

STRECKEISEN, A.L. 1976. To each plutonic rock its ${ }^{p}$ roper name. fartli Sei. Rev., 12:1-33.

TAGLIANI, T.R.M. \& GOMES, J.R.C. 1988. A deformação dos ortognaisses de Cratéus, Ceará. Rev. Geol. (UFC), 1:57-62

TAGLIANI, T.R.M.; GOMES, J.R.C.; ARTHAUD, M.H. 1988. A aplicação do método Fry nos ortognaisses de Cratéus, CE. Rev. Geol. (UFC), 1:63-70.

TULLIS, J.A. 1983. Deformation of feldspars. In: RIBBE, P.H. ed. Feldspar Mineralogy. Mineral. Soe. Am. ${ }^{\mathrm{p}}$. 297-323. (Short Course Note 2).

VERNON, R.H. \& FLOOD, R.H. 1988. Contrasting deformation of S- and I-type granitoids in the Lachlan Fold Bell, Eastern Austrália. Tectonophysics, 147:127-143.

VERNON, R.H.; ETHERIDGE, M.A.; WALL, V.J. 1988. Shape and microstructure of microgranitoid enclaves: indicators of magma mingling and flow. Lithos, 22:3-12.

WALL, V.J.; CLEMENS, J.D.; CLARKE, D.B. 1987. Models for granitoid evolution and source cornpositions. J. Geology, 95:731-749.

WINKLER, H.G.F. 1976. Petrogenesis of metamorphic rocks. New York, Springer-Verlag.

WHITE, S.H. 1979. Large strain deformation: report on a Tectonic Studies Group discussion meeting held at Imperial College, London. J. Struct. Geol., 1:333-339.

MANUSCRITO A666

Recebido em 11 de julho de 1990 Revisão do autor em 7 de janeiro de 1991 Revisão aceita em 13 de fevereiro de 1991 